\title{
Improving Public Health Delivery in Punjab, Pakistan: Issues and Opportunities
}

\author{
Michael Callen*, Saad Gulzar*, Ali Hasanain ${ }^{* * *}$, Abdul Rehman \\ Khan $^{* * * *}$, Yasir Khan ${ }^{* * * * *}$ and Muhammad Zia Mehmood ${ }^{* * * * * *}$
}

\begin{abstract}
Pakistan has a large and dispersed primary public health system that gives citizens access to trained doctors and staff, and to subsidized medicines. However, both the use of these facilities and health outcomes remain low. Improvements in information and communications technology provide exciting opportunities to leverage technology to improve management. This paper presents a detailed qualitative and quantitative study of the institutional context in which such interventions in the public health sector in Punjab would be trialed. We describe the structure and management of primary healthcare facilities, present selected results from a survey of a representative sample of basic health units, and identify some key issues. We also report and discuss officials' responses to the question of how services might be improved.
\end{abstract}

Keywords: Healthcare infrastructure, public sector management, Pakistan.

\section{JEL classification: I18.}

\section{Introduction}

Pakistan has a large and dispersed primary public health system that gives citizens access to trained doctors and staff, and to subsidized medicines. Both the use of these facilities and health outcomes, however, remain low. The development economics literature recognizes absenteeism

\footnotetext{
* University of California, Los Angeles.

${ }^{* *}$ New York University.

*** Assistant Professor, Lahore University of Management Sciences, Pakistan.

**** Lahore University of Management Sciences, Pakistan.

***** International Growth Centre, Pakistan.

****** Lahore University of Management Sciences, Pakistan.
}

The authors wish to thank the International Growth Centre (IGC), in particular Ijaz Nabi and Naved Hamid, and the Punjab Health Sector Reforms Program for help with the program. We are grateful in particular to Farasat Iqbal, Zubair Bhatti, and Asim Fayyaz for proposing and participating in this study. Asim Khwaja, Imran Rasul, Ali Cheema, and Farooq Naseer provided useful comments. 
as a key problem faced by underdeveloped countries across the world. The rapidly improving features and falling costs of information and communications technology (ICT) provide an exciting opportunity to improve information flows and facilitate better management of the health infrastructure.

This paper presents a detailed qualitative and quantitative look at the institutional context in which such an intervention in the public health sector in Punjab would be trialed. Section 2 describes the structure and management of primary healthcare facilities, identifying areas that require further scrutiny and action. Section 3 presents selected results from a survey of a representative sample of basic health units (BHUs), and identifies some key issues that need sustained attention. Section 4 reports officials' responses to the question of how services might be improved. Section 5 discusses some of these responses and concludes the study.

\section{Existing Organization and Management of Health in Punjab}

The public health system in Punjab is devolved to the districts, giving the province's central government in Lahore a minimal administrative role. In practice, however, the structure is far more complex. There are three significant substructures that make up the public health system in Punjab. First, on the service delivery side, hospitals are structured at various levels. Second, the administrative side largely comprises bureaucrats working at the provincial, divisional, and district levels. Finally, a monitoring system for these health facilities operates externally to the department.

\subsection{Organization of Service Delivery}

Punjab has about 3,000 medical facilities delivering heavily subsidized healthcare to the public. These facilities are broadly divided into five types: (i) BHUs, (ii) rural health centers (RHCs), (iii) tehsil headquarter (THQ) hospitals, (iv) district headquarter (DHQ) hospitals, and (v) teaching hospitals. Figure 1 illustrates this hierarchy. 
Figure 1: Hierarchy of public hospitals in Punjab

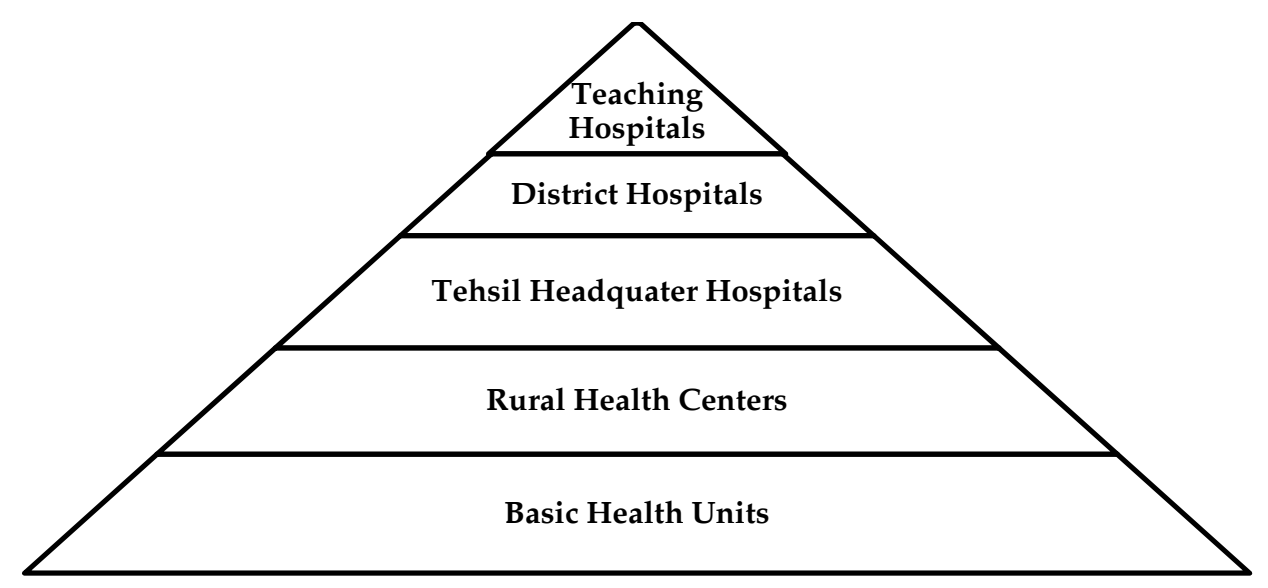

\subsubsection{BHUs}

There are 2,496 BHUs spread across the length and breadth of the province $^{1}$. These are supposed to provide the vast majority of public health services and are the first stop for rural households seeking medical attention. In most cases, they serve the population of roughly one union council $^{2}$ each, but in some cases there are two facilities per union council.

As Figure 2 shows, there is wide variation in the number of BHUs per district. This variation translates into the average rural population per BHU as presented in Figure 2-A. Rajanpur, with the fewest BHUs of all the districts, has a higher rural population per BHU—close to 30,000 people. In Faisalabad, on the other hand, a BHU serves on average fewer than 20,000 rural patients. There is, therefore, no relationship between the size of a rural population and number of BHUs in a district.

\footnotetext{
${ }^{1}$ List of BHUs provided by Punjab Health Sector Reforms Program.

2 A union council is a collection of revenue villages and can be regarded as the smallest administrative unit for various state organs.
} 
Figure 2: Distribution of BHUs across districts

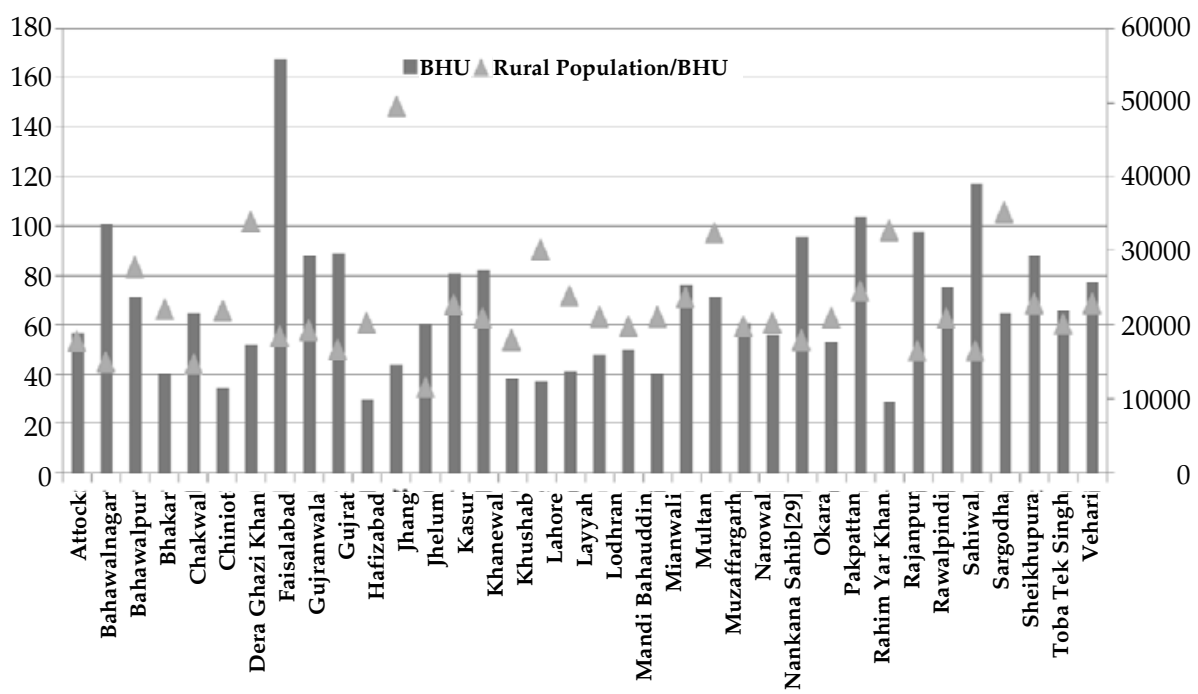

The BHUs are staffed by a small number of personnel that provide preventive and primary healthcare services. Each unit has a doctor or medical officer (MO) who also serves as the BHU's administrative head. The doctor is supported by a female health visitor (known as a "lady health visitor"), a dispenser, and occasionally a health technician. Every BHU also serves as a center for five to six roving female health workers (or "lady health workers"), a vaccinator, and a school health and nutrition supervisor. These roving workers provide door-to-door preventive healthcare services and run awareness campaigns.

\subsection{2. $\mathrm{RHCS}$}

While BHUs are almost ubiquitous in rural areas, they have limited usefulness for patients seeking slightly advanced but not specialized care. To serve such patients, the health system has established a tier of facilities known as RHCs. There are about 290 RHCs across the province.

RHCs are better equipped than BHUs to manage minor emergencies and surgeries. They also have better diagnostic facilities, since most are equipped with basic laboratories. Each unit is staffed by two to three doctors, who are supported by dispensers, female health visitors, and nurses. Unlike BHUs, these centers operate for longer hours to deal with emergencies, so their staff works in shifts. In some cases, the government has appointed specialists apart from general physicians to these facilities. 
As with BHUs, the decision to locate RHCs does not seem to account for variations in population per facility across districts: there is wide variation in both the number of RHCs and the rural population per RHC, as demonstrated by Figure 3.

Figure 3: Distribution of RHCs across districts

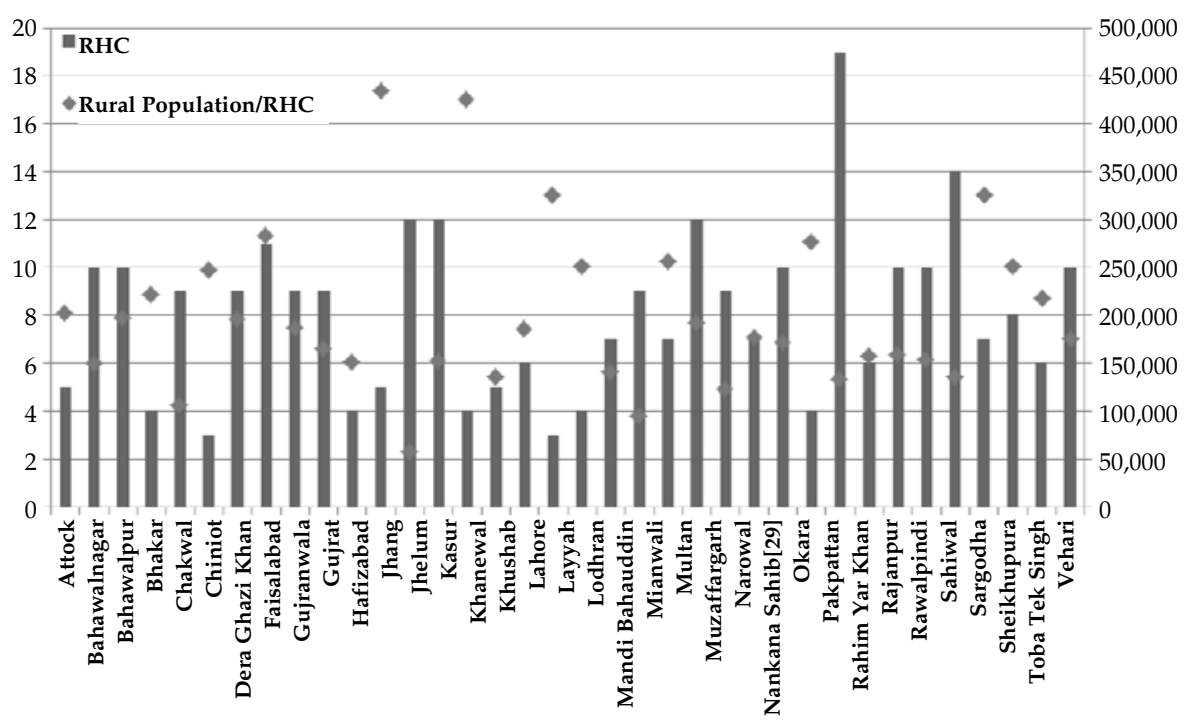

\subsubsection{THQ and DHQ Hospitals}

All tehsils and districts in the province are provided with large hospitals that are usually the most advanced healthcare facilities available in regions far from large cities. Administratively, these hospitals are run by senior doctors or medical superintendents who oversee a medical staff that comprises doctors, nurses, and other technicians. These facilities are almost exclusively located in urban centers and towns. There are $34 \mathrm{DHQ}$ and 88 THQ hospitals in Punjab.

\subsubsection{Teaching Hospitals}

There are 23 teaching hospitals in the province, of which 11 are in Lahore. These hospitals deal with most advanced healthcare requirements and prepare doctors and paramedical staff for future needs. The hospitals are located in urban centers, almost exclusively in divisional headquarters. Four divisions-Sahiwal, Dera Ghazi Khan, Gujranwala, and Sargodhado not have any teaching hospitals. 


\subsection{Administration of the Health Department}

The administration of the health system is divided between the province, divisions, districts, and tehsils (see Figure 4). The health secretary is the administrative head of the Health Department, and provides policy guidance and oversight. The department has established a separate unit, the Directorate General of Health Services, to look after the day-to-day workings of the healthcare system. The unit is headed by a director general (DG) who reports directly to the health secretary.

The directorate receives administrative support from the divisional and district health offices. The district health department has major responsibility for ensuring the proper provision of healthcare in public sector hospitals. The department is headed by an executive district officer (EDO) for health. The district department is part of the district government, which is headed by a district coordination officer (DCO). In a problem common to many departments, the EDO has two lines of reporting: he/she is not only part of the Health Department, but also of the district government. This means the EDO is answerable to the DCO for the workings of the hospitals and also to the Directorate General of Health Services. The extent of the DCO's involvement varies from district to district, depending more on his/her administrative style rather than any institutional arrangement.

The EDO oversees the provision of preventive and curative health services provided by the district's health facilities and roving workers programs. In managing these services, the EDO is supported by a district officer (DO) for health and deputy district officers (DDOs) for health. 
Figure 4: Administrative setup of the Health Department

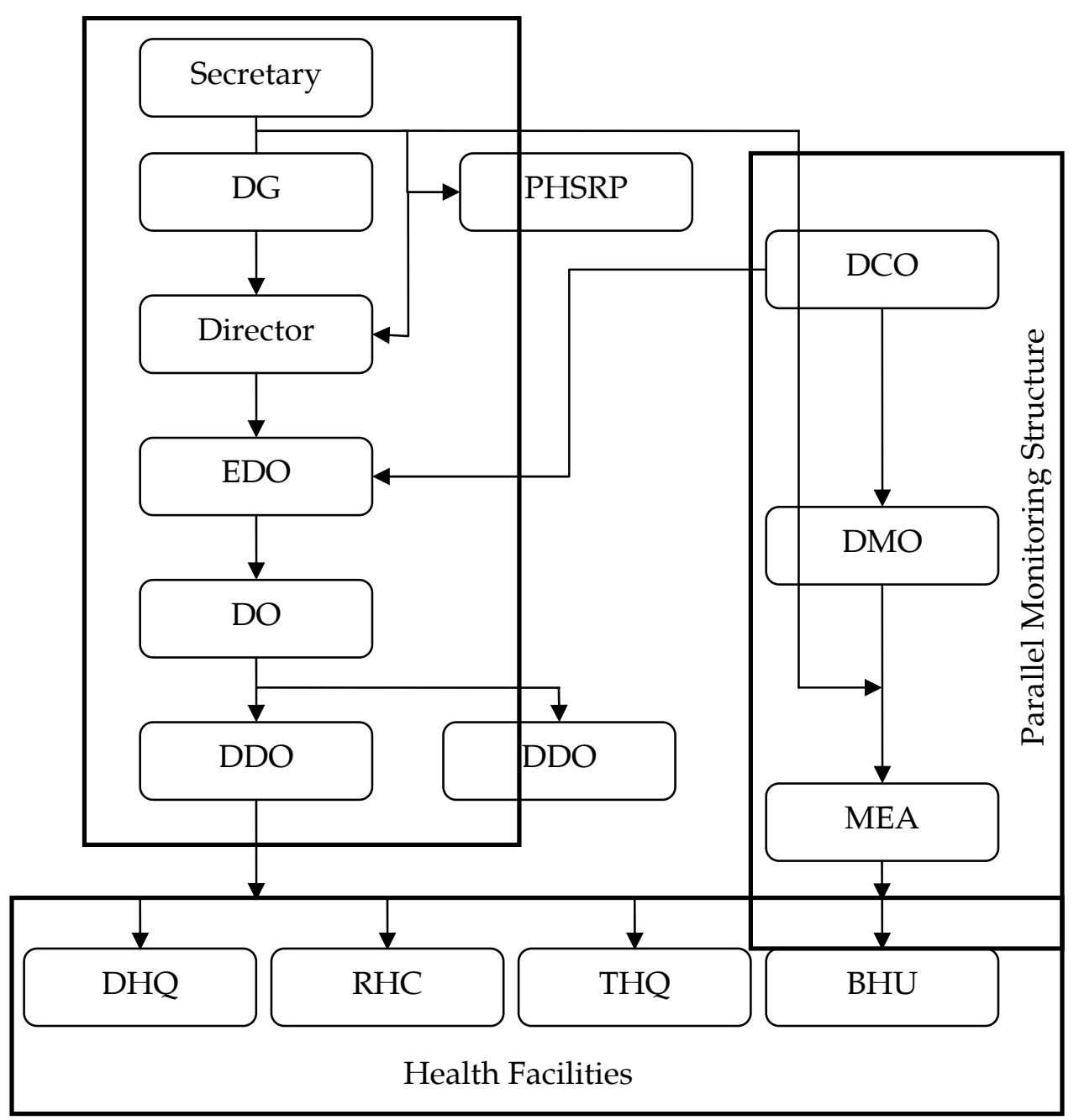

The DDO is the main officer responsible for running the health system at the tehsil or subdistrict level. He/she supervises the health staff and is entrusted with ensuring that the government facilities continue to provide free or heavily subsidized medical aid. Figure 5 gives the average number of BHUs and RHCs per tehsil in each district. Since each tehsil is looked after by a DDO, the graph can also be read as the number of average facilities that a DDO is responsible for looking after.

Besides the general management of the system, the DDO is required to visit the hospitals in his/her jurisdiction to carry out random checks of the facilities and staff working there. The DDO thus ensures that 
staff members-in particular, doctors-are attending to their duties, that there are sufficient medical supplies, and generally that the facilities are functional, staffed, and well equipped. A DDO has the authority to verbally sanction an absent officer or report him/her to the senior district officer for further action. In cases that involve contractual staff who are not permanent government employees, the DDO can recommend withholding their salary for a number of days based on performance.

Figure 5: Average number of facilities per tehsil, by district

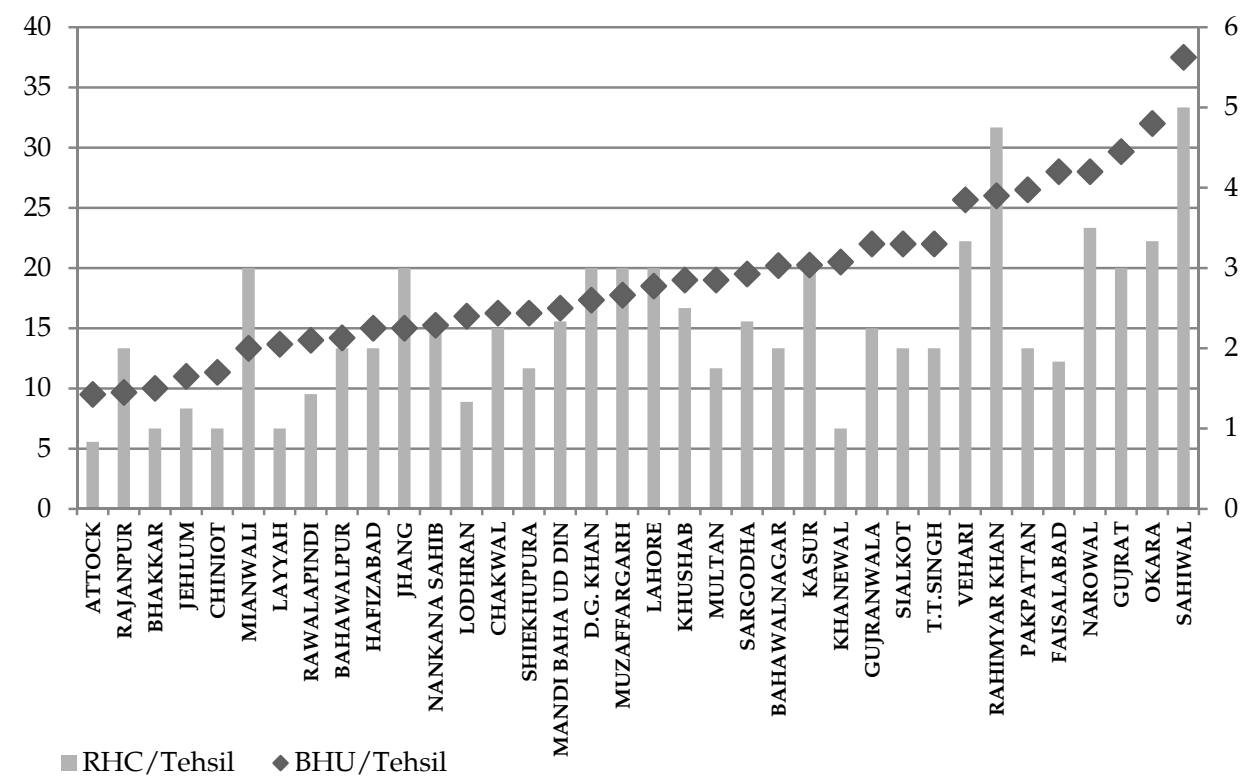

The process of reporting information based on monitoring visits tends to be very informal and is not standardized. The department's previous halfhearted efforts to standardize data collection did not change anything. Senior managers were not sure if the data being provided was reliable or whether it had been fabricated in the DDOs' offices.

The mechanism to use this data at the center was also very weak. While some effort was made to create standard indicators on which each district was to report its performance to the secretariat every month, it was unclear how the information needed to construct such indicators should be collected from the field. In general, the existing practice for DDOs was to record information in their diaries as and when it received and to report it to the EDO's office sporadically. The statistical officer at the EDO's office then used that information to construct the indicators and send an electronic report to the DG's office through a district health information system. 
Unsurprisingly, the indicators received in this manner were seldom reliable enough to be used as a basis for policy decisions. Nonetheless, the Health Department continued to hold a monthly meeting in Lahore with all the EDOs at which these indicators and the data from the monitoring and evaluation system (see Section 2.3) was discussed in detail.

Given the large number of BHUs, DDOs spend most of their time visiting these units. As discussed above, the number of BHUs per district varies, which in turn implies a varying workload for each DDO. Since each DDO is usually responsible for one tehsil, we have reported the average workload per DDO in a district in Figure 2. These averages show large variations: some DDOs are required to visit close to $40 \mathrm{BHUs}$ in a month (e.g., in Sahiwal) while others might have as few as about 10 visits to make. One confounding factor that the graph does not represent, however, is that some DDOs have multiple charges: in some cases, they may be responsible for more than one tehsil, which increases their workload significantly.

This variation in DDOs' workload results in a nonuniform structure of monitoring across the districts. In places where the DDO has a manageable number of BHUs to oversee, the existing monitoring system may work. On the other hand, places with almost 40 BHUs per officer present a structural flaw in the system in the sense that even the most diligent officer would struggle to conduct sufficient visits. Such a flaw usually results in lack of monitoring, which manifests itself in high absenteeism and the breakdown of public health delivery.

The department has also established a special unit outside the secretariat known as the Punjab Health Sector Reform Program (PHSRP). This unit is tasked with starting special projects aimed at reforming the department's governance and accountability systems with technical and financial support from donor agencies. The PHSRP also serves as a hub for collecting data from the monitoring and evaluation teams that serve all the districts.

\subsection{Monitoring and Evaluation Assistants}

Even though the Health Department has an extensive system in place for monitoring Punjab's healthcare facilities through regular visits by DDOs and senior district staff, there is also an independent monitoring structure in the province. The chief minister's monitoring task force was established in 2004 to counter the rampant absenteeism and lack of quality education in public schools in Punjab. The monitoring team is based at the 
district level and initially reported to the additional chief secretary. At the district level, the team comprises monitoring and evaluation assistants (MEAs) and a district monitoring officer. There are roughly 900 MEAs across the province who conduct monitoring visits on a daily basis.

In 2007, the MEAs were assigned the additional task of inspecting health facilities. They conduct one visit per month to a health facility up to the DHQ hospital level. Alternate MEAs carry out random visits to counter the possibility of collusion with the staff. A large amount of information is collected on a standardized form developed by the PHSRP. These forms are collected at the district level and sent to the PHSRP in Lahore, which has established a data entry center where the forms are digitized. This data is then used to calculate the performance ranking of each district.

The process of first collecting data manually and then sending the forms to the district headquarter, which subsequently sends it to Lahore, is long and tedious. By the time the data becomes available to policymakers, it is about three months old and cannot be used for any rapid policy actions. It is worth noting that this is the only formal information system (besides the DDO reports) that keeps the Health Department apprised of medicine availability, attendance of health staff, and the number of vaccinations-one of the reasons that the government so frequently lags behind in allocating medicines to hospitals.

\section{Survey: Methodology and Results on Attendance}

In late 2011, our team conducted an initial wave of data collection by surveying a representative sample of 850 out of roughly 2,500 BHUs in the province. Under our guidance, independent surveyors visited each facility unannounced in the guise of a walk-in citizen patient. Respondents were asked a large number of questions, but we report here only those responses directly linked to attendance.

\subsection{Attendance and Postings are Weak}

The first lesson we learned from this survey-and the first-order problem of health service delivery that the survey identified-was that of attendance. Of the 850 BHUs visited during working hours, 61 were closed. Furthermore, of those that were found to be open, on average 52.4 percent of the essential staff assigned to each BHU was unavailable to cater to patients.

Given that the MO is usually considered the administrative head of a BHU in addition to being the only staff member authorized to write 
prescriptions, his/her presence during working hours is crucial for the facility to function properly. We found that the MO's post was vacant in 35 percent of the BHUs visited. Moreover, of the 535 cases in which an MO was posted to the facility, he/she was absent in 269 of them. From the perspective of a patient seeking treatment, whereby there is no distinction between a doctor not being posted and a doctor being posted but not being present, the data show that a doctor was effectively unavailable in 67.7 percent of the facilities surveyed.

Absenteeism in dispersed public facilities such as schools and clinics is endemic in the developing world; it tends to be worse in smaller clinics manned by a single doctor (Chaudhury \& Hammer, 2004). However, what is alarming is that the percentages we recorded are among the worst when compared to similar surveys in other developing countries: India has a recorded absence rate of 40-45 percent (Banerjee, Deaton, \& Duflo, 2004a, 2004b); Indonesia, 40 percent; Uganda, 37 percent; Bangladesh, 35 percent; and Peru, 25 percent (Chaudhury, Hammer, Kremer, Muralidharan, \& Rogers, 2006). Similarly, the vacancy rate also compares unfavorably with that of other developing countries.

\subsection{Inspections are Weak}

The question that arises from our first result is: why is this weak attendance not being acted on? Our next result suggests this is because higher officials do not inspect the facilities as often as they are mandated to. Attendance does not improve because the inspectors do not make the visits necessary to learn about and act on staff absence. This is clear from our next series of questions.

All district health officers are expected to regularly visit BHUs to carry out inspections. However, their principal responsibility is to cover all the facilities in the districts. Due to the variation in the facilities-to-officer ratio, the frequency of visits scheduled for a BHU varies across tehsils and districts, as discussed above. Typically, a BHU is supposed to be inspected at least once a month by the DDO concerned. BHUs in the district with the highest facilities-to-officer ratio are supposed to be visited at least once every two months. BHUs in smaller districts are scheduled for two inspections a month by the DDO.

The data in Table 1 show that 51.6 percent of BHUs had been inspected by the DDO concerned in the same month we visited or the month before. About 23.3 percent had been visited before that, but within 
the preceding six months, while 11.4 percent were last visited more than six months ago. Finally, the staff of 13.8 percent of the sample BHUs could not remember the last time a DDO visited the facility for an inspection.

Table 1: Most recent visit by a DDO

\begin{tabular}{lc}
\hline When was the last time a DDO visited this BHU? & Percent \\
\hline This calendar month & 19.31 \\
Last calendar month & 32.28 \\
In the last six months & 23.28 \\
More than six calendar months ago & 11.38 \\
Don't know & 13.76 \\
\hline
\end{tabular}

The EDO is not responsible for inspecting all facilities, but he/she is still required to make at least 15 visits to any randomly selected BHUs in the district. As Table 2 shows, only 27.9 percent of the facilities reported having been inspected by the EDO in the month we visited or the month before. About 25.5 percent of the sample BHUs were last visited by the EDO before that, but within the preceding six months. Moreover, 353 facilities were either visited more than six months ago or had no record of the last time the EDO visited.

Table 2: Most recent visit by an EDO

\begin{tabular}{lc}
\hline When was the last time an EDO visited this BHU? & Percent \\
\hline This calendar month & 2.77 \\
Last calendar month & 25.10 \\
In the last six months & 25.50 \\
More than six calendar months ago & 17.44 \\
Don't know & 29.19 \\
\hline
\end{tabular}

These results strongly support the idea that weak management by district officers, particularly with regard to attendance, is a first-order problem in improving the management of government health facilities. The fact that this weakness is widespread points to a systematic failure to give district managers the incentive to curtail absence. However, it is not the only candidate area for reform. In the next section, we report respondents' own suggestions for improving the BHU/health system. 


\section{Suggestions from the Clinics}

As part of our survey, we also asked staff members for their opinion of how the BHU could be made more effective. We received a total of 7,077 recommendations based on what respondents perceived to be the main problems in the system. These can be classified into four broad categories: addressing (i) supply failure, (ii) service provision expansion, (iii) human resource improvement, and (iv) miscellaneous. About 118 responses suggested there was no need for any change.

Figure 6 illustrates the distribution of these recommendations. The three most important areas identified were (i) expanding service provision, i.e., making available services that were hitherto either not supplied at all or undersupplied; (ii) addressing supply failure, i.e., fixing supply chain and maintenance-related issues; and (iii) improving human resource management.

\section{Figure 6: Recommendations by BHU personnel}

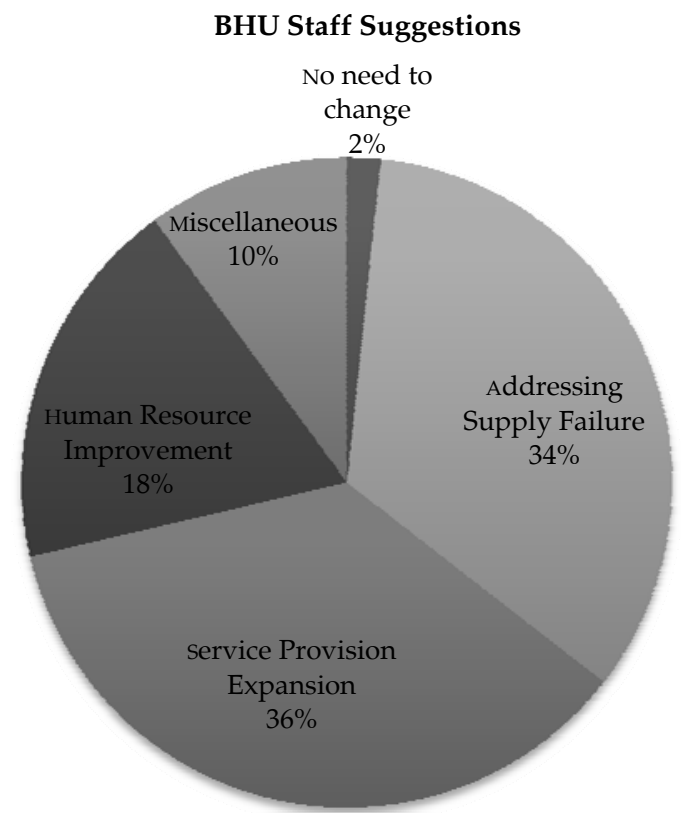

The complete taxonomy, with each category further divided into subcategories is presented in Figure 7. The detailed distribution of recommendations within these subcategories is given in Figures A1 through A4 in the Annex. 
Figure 7: Taxonomy of recommendations

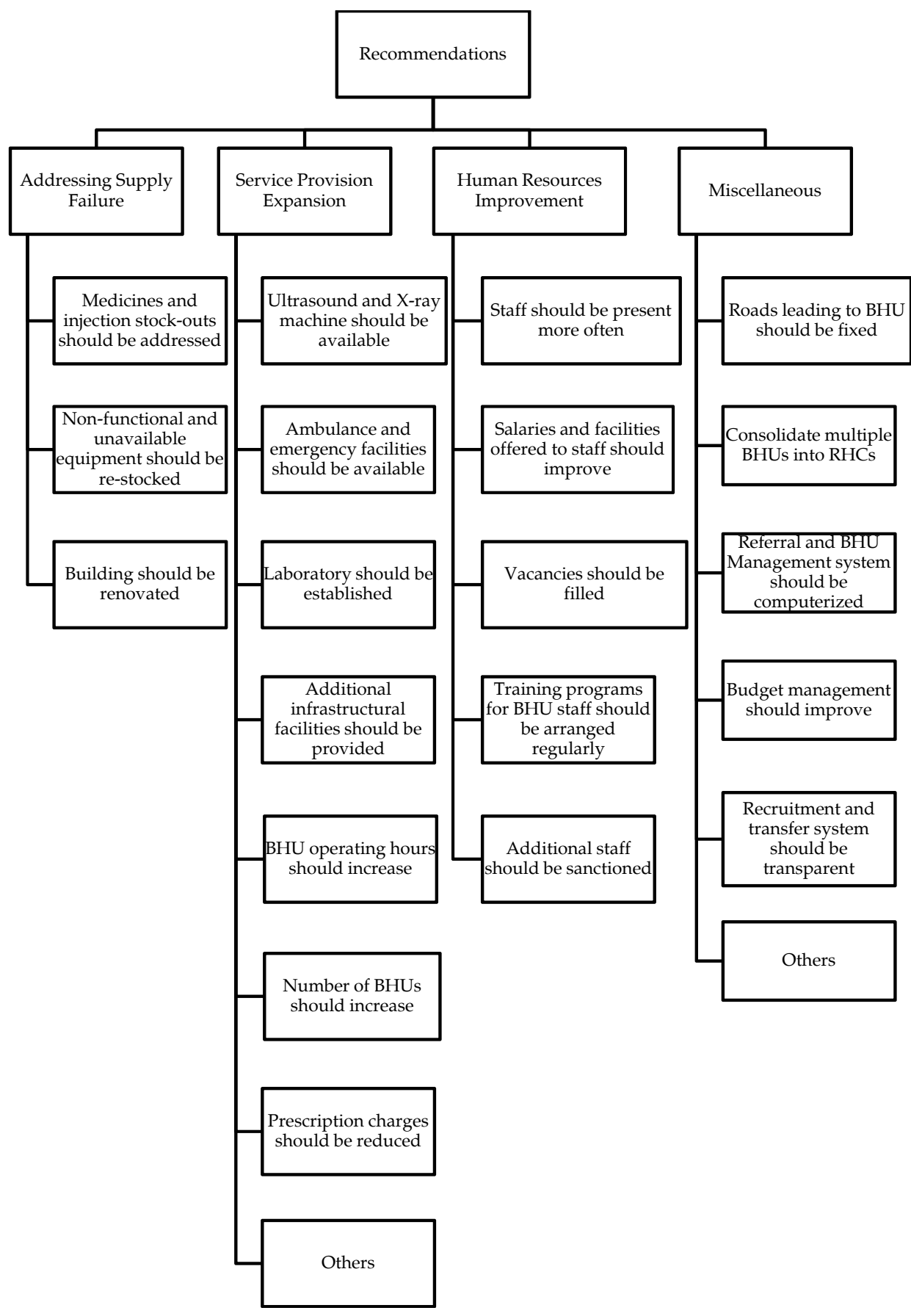

Table 3 records the frequency of the most common subcategories of recommendations that we observed. 
Table 3: Most common recommendations

\begin{tabular}{lcc}
\hline Recommendation subcategories & Frequency & $\begin{array}{c}\text { Percentage } \\
\text { of total }\end{array}$ \\
\hline $\begin{array}{l}\text { Medicines and injection stock-outs should be } \\
\text { addressed }\end{array}$ & 1,232 & 17.40 \\
$\begin{array}{l}\text { Ultrasound and X-ray machines should be available } \\
\begin{array}{l}\text { Nonfunctional and unavailable equipment should be } \\
\text { restocked }\end{array}\end{array}$ & 614 & 8.68 \\
$\begin{array}{l}\text { Ambulance and emergency facilities should be } \\
\text { available }\end{array}$ & 561 & 7.93 \\
$\begin{array}{l}\text { Building should be renovated } \\
\text { Staff should be present more often }\end{array}$ & 556 & 7.86 \\
$\begin{array}{l}\text { Laboratory should be established } \\
\text { Salaries and facilities offered to BHU staff should be }\end{array}$ & 466 & 6.58 \\
$\begin{array}{l}\text { improved } \\
\text { Additional infrastructural facilities should be }\end{array}$ & 423 & 6.23 \\
provided & 395 & 5.98 \\
Vacancies should be filled & 342 & 4.83 \\
\hline
\end{tabular}

The availability of medicines and injections is by far the most commonly voiced concern. Almost one in five respondents cited the lack of medicines as the most important constraint to improving service.

In their own reported prioritization, staff rank their own attendance as only the fifth most important problem to rectify. Filling vacancies is ranked tenth. Combined, improving attendance and filling vacancies account for just over 11 percent of all recommendations. Given the strongly negative result we report in our survey, this problem seems to be severely under-emphasized in staff members' own reports. Presumably, this is because reporting poor performance within their own cohort might lead to greater scrutiny of their own work in the future. In view of this, we believe that managers should not allow these results to cloud the first-order importance of absence and vacancies as roadblocks to a better performing health system in Punjab.

The cautionary note above notwithstanding, there is a striking concentration of recommendations. The top five subcategories reported above comprise just over half of all recommendations submitted; the top ten listed in Table 3 combined comprise just under 79.66 percent of the total. Moreover, the three broad categories earlier identified as the most important are the only ones represented in the top ten. 
To sum up, health center personnel across Punjab are remarkably unequivocal in identifying the key issues that plague their clinics and, by extension, the system as a whole. This clarity certainly helps the health sector worker identify most major problems. However, as our survey suggests, this list may continue to carry blind spots that reflect respondents' positional or intentional biases, or simply their lack of awareness about relevant issues.

\section{Problems and Opportunities}

This paper identifies at least six important lessons for Punjab's health sector managers. First, there are, clearly, faults in the geographical distribution of facilities: facilities are distributed unevenly compared to the population catchment area, and need to be relocated. Second, not only does this mean there are more doctors per facility in some areas at the expense of others (to the detriment of patients), it also means that the administrative (monitoring) workload of district officers is uneven.

Third, facility attendance of health workers is extremely weak, and fourth, vacant positions are left unfilled on a very large scale. One proximate cause for this may be that, fifth, the inspection regime run by the district officers does not perform well: doctors posted to facilities may not show up to work because their superiors do not show up to inspections. Sixth, there is widespread demand for the availability of medicines in the province and, more generally, the department must focus on supply chain improvements, adding new services, and improving management.

The recent literature on development economics recognizes absenteeism among health workers as a major constraint to improving health services (Banerjee \& Duflo, 2006). Seminal studies such as Banerjee, Duflo, and Glennerster (2008) report the difficulty of correcting this problem in poor countries with insufficient oversight, since reform efforts have a temporary effect before managers and workers find a way to return to the status quo.

Absenteeism afflicts both public and privately run centers that are geographically dispersed (and likely far removed from their principals). Duflo, Hanna, and Ryan (2012) demonstrate a promising solution for the private and nonprofit sector: they show that the use of monitoring coupled with a system of rewards and punishments can significantly improve attendance. However, this solution may not be appropriate to the public sector, where workers may enjoy political power, which insulates them from significant punishment. 
Another promising development has been the introduction of ICT. This is because of the confluence of enabling factors. First, advances in cellphone technology coupled with the falling cost of handsets has made it technologically possible to aggregate large amounts of previously dispersed data. Second, government deregulation of the telecom sector in Pakistan has led to the widespread adoption of cellphones. The Multiple Indicator Cluster Survey reports that about 70 percent of households in Punjab have at least one cell phone. Even in the poorest quintile, 20 percent report cell phone ownership. In related ongoing work, we evaluate an innovative smartphone technology to facilitate the flow of information on attendance up the organizational hierarchy. Preliminary evidence confirms both the difficulty of fixing absence and the promise of technology.

Ultimately, however, it is unlikely that a panacea exists for the problem of absenteeism. Practitioners will have to attempt a wide variety of solutions in order to achieve incremental progress.

\section{Conclusions}

We have provided a detailed contextualization of the structure of the health bureaucracy in Punjab. We have also reported selected results from an independent survey of health facilities, along with officials' suggestions for improving the system. Our main findings from these two sources are that absence and the unavailability of medicine are major problems. Both these problems stem from managerial, not financial, constraints. ICT could prove a source of potential future reform. It is up to future work in this area to harness this potential. 


\section{References}

Banerjee, A., Deaton, A., \& Duflo, E. (2004a). Healthcare delivery in rural Rajasthan. Economic and Political Weekly, 39(9), 944-949.

Banerjee, A., Deaton, A., \& Duflo, E. (2004b). Wealth, health, and health services in rural Rajasthan. American Economic Review, 94(2), 326330.

Banerjee, A., \& Duflo, E. (2006). Addressing absence. Journal of Economic Perspectives, 20(1), 117-132.

Banerjee, A., Duflo, E., \& Glennerster, R. (2008). Putting a band-aid on a corpse: Incentives for nurses in the Indian public healthcare system. Journal of the European Economic Association, 6(2-3), 487500 .

Chaudhury, N., \& Hammer, J. (2004). Ghost doctors: Absenteeism in rural Bangladeshi health facilities. World Bank Economic Review, 18(3), 423-441.

Chaudhury, N., Hammer, J., Kremer, M., Muralidharan, K., \& Rogers, F. H. (2006). Missing in action: Teacher and health worker absence in developing countries. Journal of Economic Perspectives, 20(1), 91116.

Duflo, E., Hanna, R., \& Ryan, S. P. (2012). Incentives work: Getting teachers to come to school. American Economic Review, 102(4), 1241-1278. 
Annex

Table A1: Survey summary statistics (selected)

\begin{tabular}{lccc}
\hline Variable & Obs. & Mean & Std. dev. \\
\hline BHU was open at the time of visit & 848 & 0.928066 & 0.258531 \\
Doctor present (unconditional) & 823 & 0.323208 & 0.467986 \\
Doctor present (conditional) & 535 & 0.497196 & 0.50046 \\
Doctors assigned & 823 & 0.650061 & 0.477241 \\
Health technician present (unconditional) & 822 & 0.372263 & 0.483702 \\
Health technician present (conditional) & 617 & 0.495948 & 0.500389 \\
Health technicians assigned & 822 & 0.750608 & 0.432924 \\
Dispenser present (unconditional) & 821 & 0.741778 & 0.437923 \\
$\begin{array}{l}\text { Dispenser present (conditional) } \\
\text { Dispensers assigned }\end{array}$ & 792 & 0.768939 & 0.421778 \\
Lady health visitor present (unconditional) & 821 & 0.964677 & 0.184707 \\
Lady health visitor present (conditional) & 773 & 0.607795 & 0.48854 \\
Lady health visitors assigned & 821 & 0.645537 & 0.478656 \\
$\begin{array}{l}\text { School health and nutrition supervisor present } \\
\text { (unconditional) }\end{array}$ & 820 & 0.343902 & 0.234764 \\
$\begin{array}{l}\text { School health and nutrition supervisor present } \\
\text { (conditional) }\end{array}$ & 757 & 0.372523 & 0.483796 \\
$\begin{array}{l}\text { Midwife present (unconditional) } \\
\text { Midwife present (conditional) }\end{array}$ & 818 & 0.506113 & 0.500269 \\
$\begin{array}{l}\text { Number of polio vaccinations in the last month } \\
\text { (unweighted) }\end{array}$ & 744 & 0.556452 & 0.497137 \\
$\begin{array}{l}\text { Number of polio vaccinations in the last month } \\
\text { (weighted) }\end{array}$ & 628 & 264.7357 & 799.8425 \\
$\begin{array}{l}\text { Number of antenatal care clients in the last } \\
\text { month (unweighted) }\end{array}$ & 562 & 56.74555 & 51.75568 \\
$\begin{array}{l}\text { Number of antenatal care clients in the last } \\
\text { month (weighted) }\end{array}$ & 560 & 23.5917 & 25.5131 \\
\hline & & & \\
\hline
\end{tabular}




\section{Figure A1: Suggestions for improving supply}

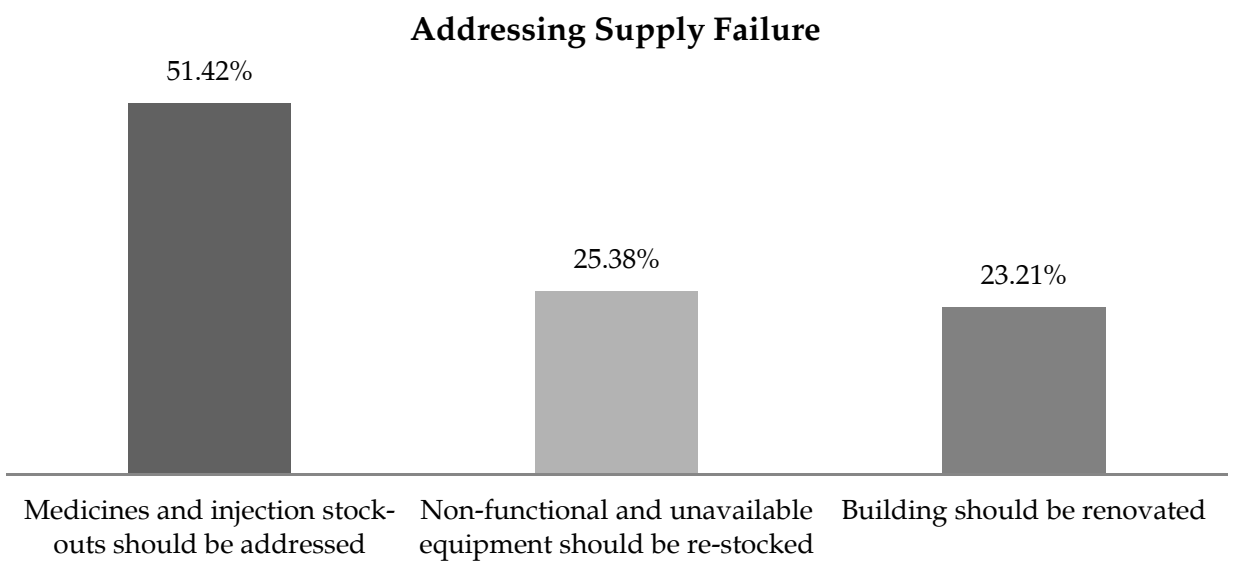

Figure A2: Suggestions for expanding services

Service Provision Expansion

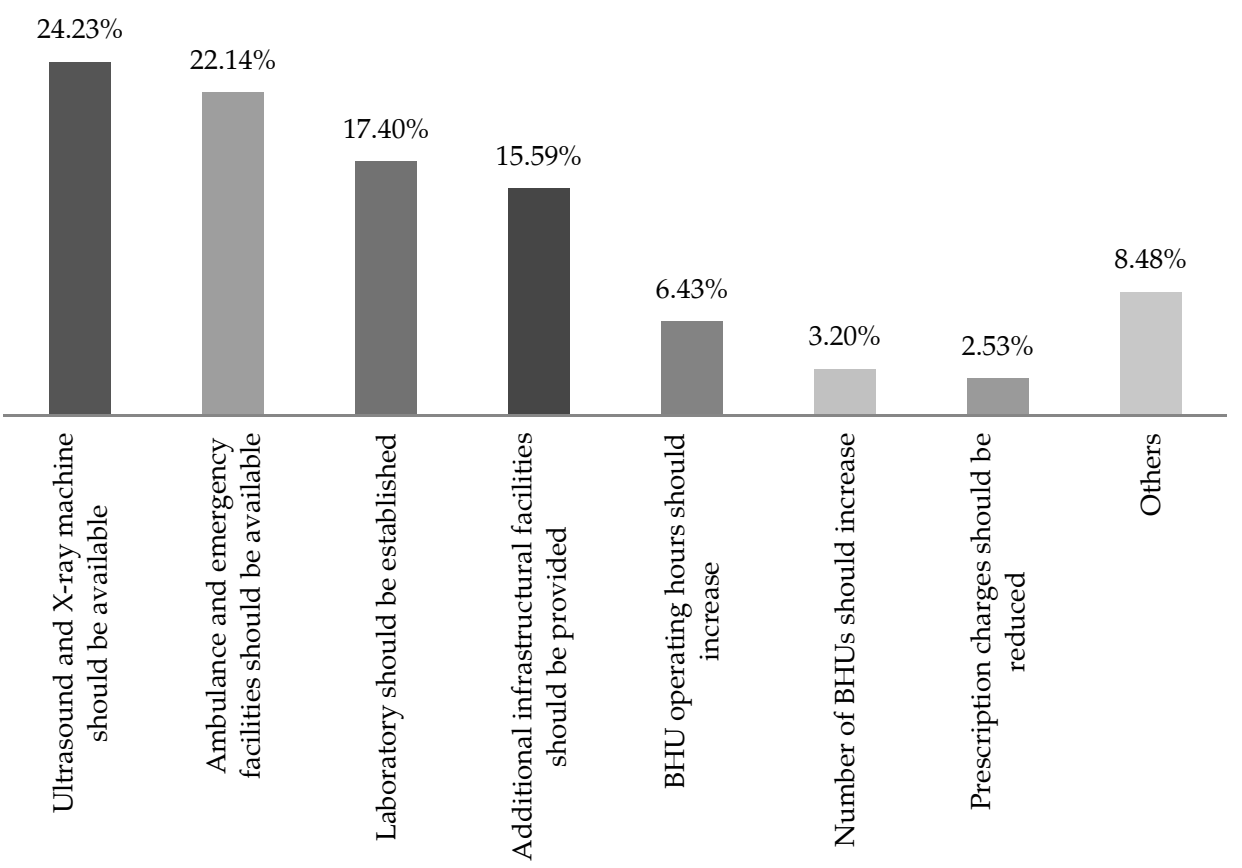




\section{Figure A3: Suggestions for improving human resources}

\section{Human Resource Improvement}

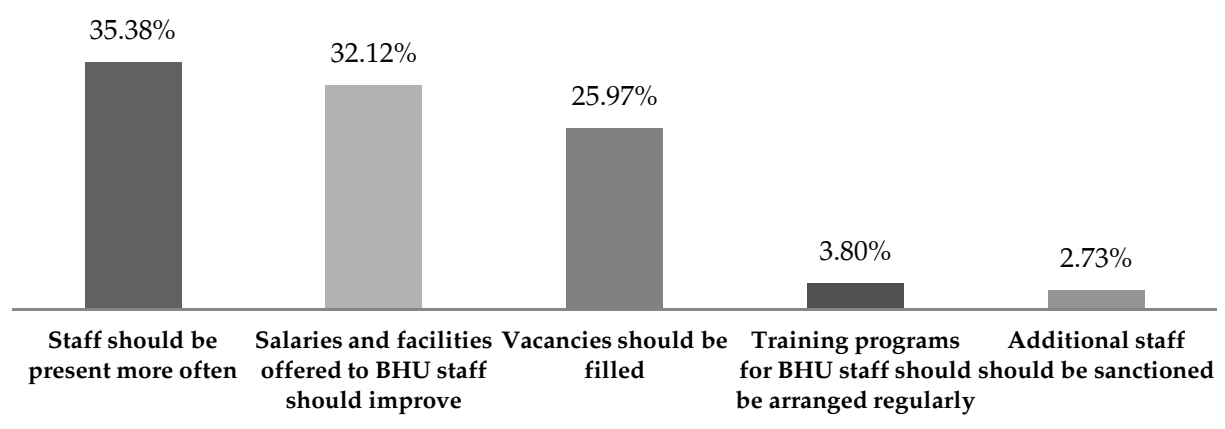

Figure A4: Miscellaneous suggestions

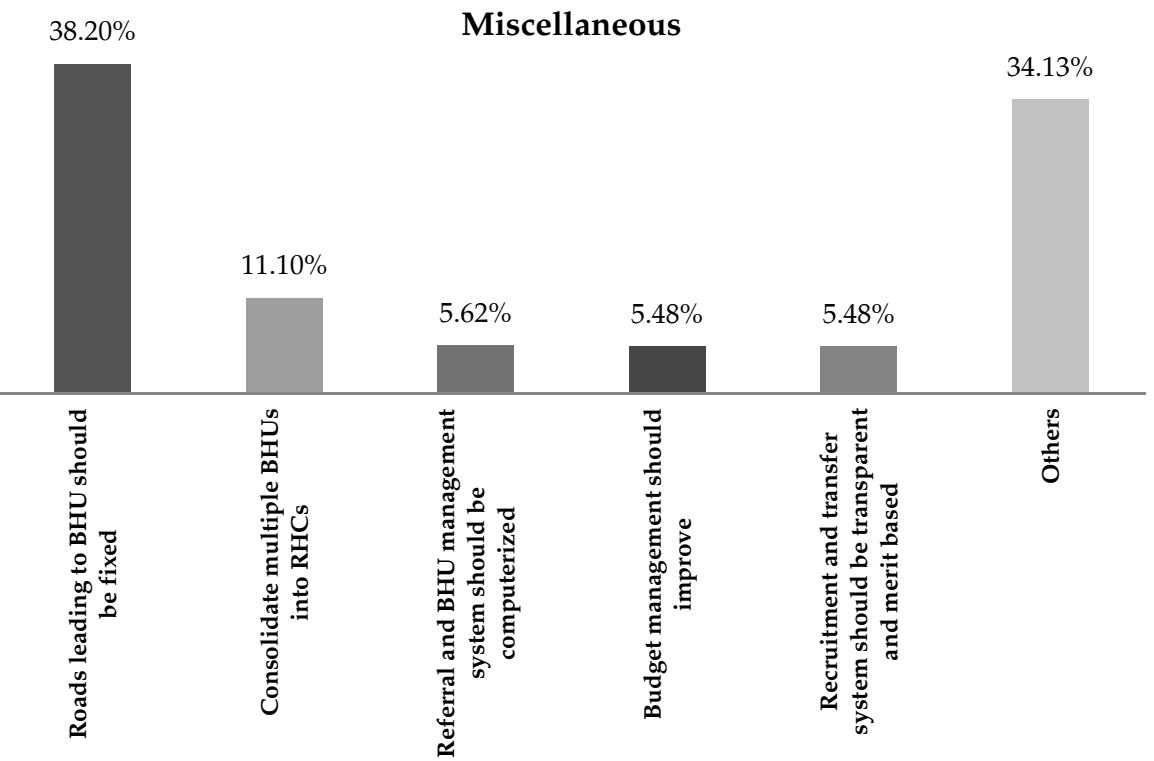

